\title{
Suppression of Banana Fusarium Wilt Disease With Soil Microbial Mechanisms Via Pineapple Rotation and Residue Amendment
}

\author{
Jinming Yang \\ Hainan University \\ Zongzhuan Shen \\ Nanjing Agricultural University \\ Xiangyu Ren \\ Hainan University \\ Wei Gao \\ Hainan University

\section{Yutong Wang} \\ Hainan University \\ Manyi Liu \\ Hainan University

\section{Shan Hong} \\ Hainan University \\ Mingze Sun \\ Hainan University \\ Yan Zhao \\ Hainan University \\ Yunze Ruan \\ Hainan University \\ Beibei Wang ( $\square$ wangbbhaida@163.com ) \\ Hainan University
}

\section{Research Article}

Keywords: Fusarium wilt disease, Crop rotation, Bulk and rhizosphere soil microorganisms, Plant residues, Disease suppression

Posted Date: November 3rd, 2021

DOI: https://doi.org/10.21203/rs.3.rs-1015644/v1

License: (c) (1) This work is licensed under a Creative Commons Attribution 4.0 International License. Read Full License 


\section{Abstract}

Aims The large outbreak of banana Fusarium wilt has become a bottleneck limiting the industry's development, and crop rotation is a costeffective and essential measure to overcome the obstacles of banana crop monoculture. The present work was carried out to explore the mechanisms of how changes in physicochemical properties and the reestablishment of soil microorganisms in high-incidence soils are affected by crop rotation and plant residue.

Methods In this study, pineapple-banana crop rotation and pineapple residue amendment were used to alleviate banana Fusarium wilt, and their effects on bacterial and fungal communities were studied using the MiSeq Illumina sequencing platform.

Results Both pineapple-banana rotation and residue addition significantly reduced disease incidence. Moreover, pineapple rotation and residue amendment altered the bacterial and fungal community composition. The taxonomic and phylogenetic alpha diversity of bacteria and fungi significantly increased against disease suppression and nutrition competition. The relative abundances of the Burkholderia, Pseudomonas, Elaphocordyceps, Penicillium, and Talaromyces genera were higher, and the number of Fusarium was significantly lower in rotational soil than in banana monoculture soil. Finally, linear models (LM) was used to show that the Burkholderia and Talaromyces in crop rotation, and Aspergillus in residue amendment have significant negative relationship to disease incidence, which plays a key role in Fusarium reduction.

Conclusions To consider the economic benefits and protect the vitality of the soil, this study suggested that pineapple-banana rotation and pineapple residue amendment both could be considered for the sustainable management of banana wilt.

\section{Introduction}

Currently, soil-borne diseases are a serious threat to soil health and crop productivity (Dita et al. 2010; Mendes et al. 2013) and have become one of the major problems for the sustainable development of intensive agriculture (Butler 2013). Banana (Musa spp.) is among the crops more severely affected by succession disorders caused by multiple abiotic (poor soil fertility, drought, high temperature and salinity) and biotic (fungi, bacteria, viruses and pests) factors (Mendes et al. 2014; Huang et al. 2012; Hwang and Ko 2004), particularly strains of the fungal pathogen Fusarium oxysporum $\mathrm{f}$. sp. cubense (Foc4), this fungus has an extremely serious impact on the banana industry worldwide (Zhang et al. 2014; Wang et al. 2013; Sun et al. 2018; Ploetz and Churchill 2011).

For a long time, physical (e.g., exposure), chemical (e.g., soil fumigation) and biological (e.g., antagonistic microorganisms) methods have reduced the pathogens in the soil to some extent and have made important contributions to the effective prevention and control of soilborne diseases (Lakshmanan et al. 2008; Xue et al. 2019; Li et al. 2019; Su et al. 2017). However, currently, in high-incidence banana soil, the soil microbiota is severely imbalanced, and the short-term reduction in the pathogenic population does not fundamentally improve the imbalance of the soil microbiota (Ploetz 2015). Therefore, in high-incidence fields, to gradually restore a healthy soil microbiota, crop rotation may be an important measure for the gradual modification of soil ecology. Studies show that soil pathogens can be reduced by using specific agricultural practices, for example, the incorporation of plant residues in the soil and crop rotation (Larkin 2015; Bonanomi et al. 2018).

Crop rotation is an important measure for gradually changing the soil ecology (Li et al. 2021). Different crop rotation systems have different effects on the suppression of different diseases, such as obstructing the inbreak of pathogens, chemosensitive substances, and antagonistic microorganisms, improving soil fertility through root exudates and residues, and increasing soil microbial biomass and activity (Christen and Sieling 1995; Wang et al. 2010; Larkin and Halloran 2014; Wright et al. 2014). These strategies mostly rely on promoting the emergence of protective microbiomes or directly impacting the population of the pathogen, both of which account for effective disease control (Cunfer et al. 2006; Wang et al. 2016; Tao et al. 2020).

The soil microbiome plays an important role in promoting plant growth and development, nutrient uptake, disease resistance and adaptation to environmental stresses. Their abundance, composition and activity largely determine the sustainability of agriculture. Recent studies have shown that modulation of the soil microbiome can reduce the number of pathogens in the soil and enhance rhizosphere immunity, thereby reducing or suppressing disease occurrence. For example, Wei et al. (2019) showed that phages can "target" tomato cyanobacteria to disrupt their ability to survive while structuring the rhizosphere soil flora to restore community diversity and increasing the abundance of beneficial microbes. In addition, the abundance and activity of Pseudomonas, Sphingomonas, Penicillium and Trichoderma spp. were found to be significantly higher than the Fusarium number in the soil (Hong et al. 2020). The soil microbiome can enhance rhizosphere immunity, improve soil fertility and crop yield, maintain the persistence of plants, animals and humans, and protect soil health (Bender et al. 2016). Additionally, there are many protozoans that protect crop health by feeding on or producing beneficial antibacterial 
substances to defend against the invasion of other Fusarium pathogens (Guo et al. 2021). More interestingly, the interactions between soil microbial communities are also closely related to the ability of Fusarium to invade plants and affect their health. Studies have shown that immune rhizosphere microbial communities are more diverse and have a more complex microbial network (Ge et al. 2021). It was shown that rhizosphere competitive intercropping communities could produce more bacterial inhibitory substances or fully occupy limited ecological niches, thus effectively suppressing pathogen invasion and reducing widespread outbreaks of soil-borne diseases.

Furthermore, studies have shown that plant root exudates and residues in soil can have a long-lasting effect on pathogen control as a result of crop rotation and relieve soil pressure by improving soil properties (Hu et al. 2018; Yuan et al. 2018; Zhou et al. 2020). As such, it is clear that crop rotation and plant residue manipulation in the field are important strategies for soil-borne disease management (Mawar and Lodha 2015). However, these strategies have received relatively little attention, as efforts have mostly been given to investigate how such approaches relate to overall aspects of soil quality, nutrient cycle, and crop performance (Wang et al. 2018; Martinez-Feria et al. 2018; Chen et al. 2018). Therefore, understanding how these approaches impact the soil microbiome composition and its ecological function remains elusive (Afshan et al. 2015). This opens up potential opportunities to explore beneficial outcomes of agricultural management associated with soil-borne disease control (De et al. 2020).

In our previous work, banana-pineapple rotation was picked out for its high-efficiency in banana Fusarium wilt disease prevention and control (Wang et al. 2015). In normal farming operations, pineapple residue is returned to the field after rotation. Therefore, the effect of crop rotation consists of two parts: simple crop rotation and residue return. We hypothesize that both crop rotation and residue amendment have inhibitory effects on banana Fusarium wilt, while, how they work was still unknown. In this study, two pot experiments, crop rotation and residue amendment, were designed to study the improvement of soil physicochemical properties and their effect on soil microbiota. Further, we hypothesise that pineapple-banana crop rotation and pineapple residue addition provides greater suppression of Fusarium wilt due to improved soil physicochemical properties that stimulate the growth of indigenous beneficial microorganisms, resulting in a significant reduction in disease incidence in bananas compared to that under monoculture. The aims of this study were (1) to evaluate the effect of the pineapple-banana crop rotation system on wilt disease in banana seedlings during the seedling period, (2) to estimate the changes in microbial community structure from the bulk soil to the rhizosphere soil zone, (3) to analyse the diversity of soil microorganisms, and (4) to study the relationship between the soil microbial community composition and environmental factors.

\section{Materials And Methods}

Crop residues, root exudates and soil sampling

Preparation of banana and pineapple residues: Banana and pineapple residues were collected from a field located at Paigou village in Zhongyuan town, Qionghai City, Hainan Province, China $\left(110^{\circ} 30^{\prime} \mathrm{E}, 19^{\circ} 5^{\prime} \mathrm{N}\right)$. Briefly, the whole plants were put into plastic packaging bags, kept on ice, and transported to the laboratory $(<6 \mathrm{~h})$. These crop residues were carefully washed five times with sterile deionized water in the laboratory and divided into root, stem leaf and fruit plant parts. CK: no residue, B_L: banana stem leaf residue, B_R: banana root residue, P_L: pineapple stem leaf residue, $P_{-} R$ : pineapple root residue, and P_F: pineapple fruit residue. These crop residues were chopped into tiny pieces and ground down to powder. Each residue type was sieved through a 4-mm mesh, and the total nutrient content was measured. Fresh plant samples were dried, ground and extracted at a ratio of 1:5 plant residue: deionised water for 48 hours and aseptically filtered to obtain the extract master batch.

Preparation of banana and pineapple root exudates: The plants were removed from the soil, rinsed five times with tap water and five times with deionised water, and incubated in a plastic cup containing $300 \mathrm{~mL}$ of deionised water for $24 \mathrm{~h}$. The solution containing the root exudate was combined and then slowly filtered (filter membrane pore size: $0.45 \mu \mathrm{m}$, size: $\Phi 25 \mathrm{~mm}$ ), and the filtrate was freeze-dried to dryness. All roots of pineapple plants involved in root exudate collection were then dried and weighed separately, the freeze-dried material was dissolved separately in an appropriate amount of deionized water, and the volume was fixed to one gram of dry weight root exudate per $\mathrm{mL}$ of root exudate master batch (i.e., $1 \mathrm{~g}$ of dry root exudate per $\mathrm{mL}$ ) and stored at $-20^{\circ} \mathrm{C}$.

Plates were poured according to different volume ratios $(1: 10,1: 100,1: 1000)$ of residue extracts to water agar. Pathogen cakes were inoculated into the centre of the prepared plates with a $0.8-\mathrm{cm}$-diameter hole punch to obtain uniform growth of Fusarium acuminatum cakes of uniform media thickness. Effect of mycelia growth $(\%)=$ (diameter of treated colonies - diameter of control colonies) / (diameter of control colonies $-0.8 \mathrm{~cm}) \times 100$.

Soil with high banana Fusarium wilt disease incidence (> 65\%) was collected from the field trial site (Lingao Xinxing Farm, Hainan Province, China $\left(109^{\circ} 77^{\prime} \mathrm{E}, 19^{\circ} 77^{\prime} \mathrm{N}\right)$, where bananas were continuously cropped for 11 years. The field trial site has a tropical monsoon climate with an average annual temperature of $23.8^{\circ} \mathrm{C}$, an average precipitation of $1,786 \mathrm{~mm}$, and an annual average of 2,059 hours of

Page 3/18 


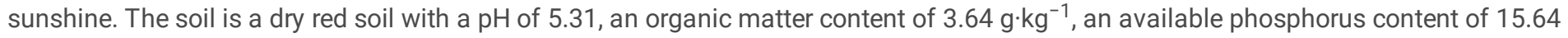
$\mathrm{mg} \cdot \mathrm{kg}^{-1}$, an available potassium content of $411.67 \mathrm{mg} \cdot \mathrm{kg}^{-1}$, and an available nitrogen content of $91.23 \mathrm{mg} \cdot \mathrm{kg}^{-1}$. The excavated field soil was collected within the drip line next to the banana plant approximately $20 \mathrm{~cm}$ deep, thoroughly mixed and immediately transferred to a greenhouse (average temperature of $36^{\circ} \mathrm{C}$ and $37 \%$ humidity) at the College of Agriculture, Hainan University, Haikou, Hainan Province, China $\left(110^{\circ} 34^{\prime} \mathrm{E}, 20^{\circ} 06^{\prime} \mathrm{N}\right)$.

Pot rotation experimental design

A pot experiment was conducted from May 2018 to February 2019. It was completely randomized and included three treatments (i.e., Treatments I-III): fallow treatment (Treatment I), banana monoculture (Treatment II), and pineapple rotation (Treatment III). Each polypropylene pot $(35 \times 25 \times 25 \mathrm{~cm}$, length $\times$ width $\times$ height $)$ had $10 \mathrm{~kg}$ of soil per pot, with six replicates of 10 pots per replicate. Before transplanting, commercial bio-organic fertilizer (a pure plant-derived bio-organic fertilizer containing $1.3 \%$ nitrogen $(\mathrm{N}$ ), $1.1 \%$ phosphorus $\left(\mathrm{P}_{2} \mathrm{O}_{5}\right), 1.0 \%$ potassium $\left(\mathrm{K}_{2} \mathrm{O}\right)$, organic matter $\geq 40 \%$, and moisture $\left.\leq 30 \%\right)$ was applied at a rate of $2 \%$ soil as a base fertilizer in the pots. After 5 days of transplanting, evenly grown pineapple and banana seedlings were transplanted into the pots. After 6 months of cultivation, planted banana seedlings exhibited mild Fusarium wilt symptoms, such as yellow leaves and scabs at the base of the stem. Subsequently, the next crop of banana seedlings was continued by pulling out pineapple and banana seedlings and planting the banana seedlings. When the maximum incidence of treatment banana (B) was greater than $80 \%$ (4 months), the incidence of banana seedlings was counted for all treatments.

At this time, the whole banana plant was removed, and the bulk and rhizosphere soil were collected with sterile tweezers or brushes. The bulk soils of fallow, banana and pineapple were defined as $\mathrm{CBF}, \mathrm{BBm}$ and $\mathrm{PBr}$, respectively, while the rhizosphere soils of fallow, banana and pineapple were defined as CRf, BRm and PRr, respectively (Fig. 1A).

Pineapple residue amendment pot experimental design

For the experiment (September 2018 to March 2019) on the effects of soil amendment with crop residue on disease severity, field experiment available crop residue, banana and pineapple (Qionghai, Hainan) were chopped and finely ground using an Oster blender and were then passed through a 2-mm mesh sieve. Crop residue was then thoroughly mixed with the pasteurized soil at a rate of $3.0 \%(\mathrm{v} / \mathrm{v})$. There were three treatments (i.e., Treatments VI-IV) designed for soil collected from the field with the same potting specifications as above. Treatment $\mathrm{VI}$ was the control: no residue added, Treatment $\mathrm{V}$ was banana residue added, Treatment $\mathrm{VI}$ was pineapple residue added. The experiment ended when the incidence of banana seedlings treated with added banana residues was over $60 \%$ (at six months). At this time, the whole banana plant was removed, and the bulk and rhizosphere soil were collected with sterile tweezers or brushes. The bulk soils of fallow, banana and pineapple were defined as $\mathrm{CBn}, \mathrm{BBb}$ and PBp, respectively, while the rhizosphere soils of fallow, banana and pineapple were defined as CRn, BRb and PRp, respectively (Fig. 1B).

\section{Disease incidence determination}

Banana plants with typical wilt symptoms, such as yellow leaves, wilted leaves, and root rot, were counted as diseased plants, and the incidence rate was expressed as the percentage of the number of diseased banana plants to the total number of planted banana plants. In other words, the incidence rate $(\%)=$ banana plants with incidence/total number of banana plants $\times 100 \%$.

Soil sampling collection and DNA extraction

Bulk soil samples were collected by removing banana plants from soil cores to a depth of $10 \mathrm{~cm}$ using a soil auger. The soil was mixed, homogenized and sieved through a 2-mm nylon sieve to remove plant debris and was then divided equally into three subsamples. One subsample was air-dried for physicochemical analysis, and the other two were stored at $4{ }^{\circ} \mathrm{C}$ and $-80^{\circ} \mathrm{C}$ for microbiological analysis and DNA extraction, respectively. At this time, the whole plant was removed, and the bulk soil was removed by careful shaking. Soil still adhering to the roots was collected with sterile tweezers and defined as rhizosphere soil. Total soil DNA was extracted using a PowerSoil DNA Isolation Kit (MoBio Laboratories Inc., Carlsbad, CA, USA) following the manufacturer's protocol. Bulk soil and rhizosphere soil samples of banana and pineapple collected from pot planting and residue addition tests were accurately weighed to $0.7000 \mathrm{~g}$ and 0.4000 g, respectively. Soil DNA microorganisms were extracted using a kit (MoBio products, USA: PowerSoil@ DNA Isolation Kit, 12888) (Wang et al. 2016). The extraction results were verified by nucleic acid assay and stored at $-20^{\circ} \mathrm{C}$ in a refrigerator. $A$ volume of $20 \mu \mathrm{L}$ of $\mathrm{DNA}$ samples from each treatment was selected and sent to "Nanjing aomike Bio" for Illumina MiSeq sequencing.

Quantitative PCR of Fusarium oxysporum in bulk and rhizosphere soil 
Quantitative real-time PCR amplification (qPCR) was performed to determine the number of F.oxysporum using total bulk and rhizosphere soil DNA as a template. The primers used were FocSc-1 and FocSc-2 (Table S1). The system for real-time fluorescence absolute quantification of pathogens at $50 \mu \mathrm{L}$ was $2 \mu \mathrm{L}$ of DNA template sample, $25 \mu \mathrm{L}$ of premix reagent, $1 \mu \mathrm{L}$ of primer 1 (FocSc-1) (10 pmol/L), 1 $\mu \mathrm{L}$ of primer 2 (FocSc-2) $(10 \mathrm{pmol} / \mathrm{L})$, and $21 \mu \mathrm{L}$ of $\mathrm{ddH}_{2} \mathrm{O}$. All soil DNA samples and the standard curve were analysed using a 7500 RealTime PCR System (Applied Biosystems ${ }^{\text {TM }}$, Foster City, USA). The melting curve and amplification efficiency were confirmed as standards for amplification. Six replicates of each sample were estimated, and the results were converted to log10 copy numbers (copy numbers $\mathrm{g}^{-1}$ soil) (Xiong et al. 2017a).

Soil chemical analysis and culturable microorganism determination

Soil pH was assayed using a soil-water ratio of $1: 5(\mathrm{w} / \mathrm{v})$ suspensions. The organic matter (OM) content was measured using the $\mathrm{K}_{2} \mathrm{Cr}_{2} \mathrm{O}_{7}$ $\mathrm{H}_{2} \mathrm{SO}_{4}$ oxidation method. Available potassium (AK) was extracted with ammonium acetate and analysed by flame photometry. Available phosphorus (AP) was determined by molybdenum antimony colorimetry, and the available nitrogen (AN) content was determined following Liu et al. (2016).

The total numbers of culturable Fusarium, bacteria, fungi and actinomycetes were determined following Shen et al. (2015a). The counts were as follows: the number of colonies forming units (CFU) formed on the plate was converted to the number of colonies formed per gram of dry soil and are expressed as CFU/g (dry soil) (Shen et al. 2015b).

Illumina MiSeq sequencing and data processing

The V4-V5 region of bacterial 16S rDNA and the fungal ITS region were amplified using the individual barcoded primers 520F/802R and ITS5F/ITS2R, respectively (Table S1) (Shen et al., 2018b). The PCR amplification procedures, including a $25-\mu \mathrm{L}$ reaction volume containing $5 \mu \mathrm{L}$ of $5 \times$ reaction buffer, $5 \mu \mathrm{L}$ of $5 \times \mathrm{GC}$ buffer, $1 \mu \mathrm{L}$ of the $10 \mu \mathrm{M}$ primer set, $2 \mu \mathrm{L}$ of template DNA, $8.75 \mu \mathrm{L}$ of ddH $\mathrm{H}_{2} \mathrm{O}$, and $5 \mu \mathrm{L}$ of 100 $\mathrm{mM}$ dNTPs for $16 \mathrm{~S}$ or $2 \mu \mathrm{L}$ of $100 \mathrm{mM}$ dNTPs and $0.25 \mu \mathrm{L}$ of DNA polymerase for ITS, were conducted according to Shen et al. (2015a). The resulting PCR products were generated using the following PCR conditions: a temperature programme of 2 min at $98^{\circ} \mathrm{C}$, followed by 28-30 cycles of $15 \mathrm{~s}$ at $98^{\circ} \mathrm{C}, 55^{\circ} \mathrm{C}$ or $50^{\circ} \mathrm{C}$ for $30 \mathrm{~s}$, and $30 \mathrm{~s}$ at $72{ }^{\circ} \mathrm{C}$. The purified amplicons were pooled in equimolar amounts and analysed with the Illumina MiSeq Aomike at Personal Biotechnology Co., Ltd. (Nanjing, China).

Raw sequences based on unique barcodes were assigned to soil samples following the QIIME software package (version 1.9.1) tutorials after elimination of the adaptors and primer sequences (Caporaso et al. 2010), and pairs of reads were merged using the FLASH software tool (version 1.2.7). The paired sequences were processed by the UPARSE pipeline to produce an operational taxonomic unit (OTU) table with USEARCH 11 and Perl scripts (Edgar et al. 2011). Briefly, sequences with a quality score $<0.5$ or length $<200$ bp were eliminated. The retained sequences were assembled to identify OTUs at $97 \%$ similarity, and chimaeras were removed based on the UCHIME method. Then, high-quality OTUs were classified with the RDP Bacterial 16S database and the UNITE Fungal ITS database of the RDP classifier procedure for bacteria and fungi, respectively (Wang et al. 2007; Kõljalg et al. 2013).

The raw sequence data have been deposited in the NCBI Sequence Read Archive (SRA) database under accession numbers PRJNA745388 and PRJNA746047.

Statistical analysis

Microsoft Excel 2010 was used to process and graph the obtained data. Data were analysed with SPSS 20.0 software, and one-way analysis of variance (ANOVA) was used to compare the data. The significance of differences between treatments was tested using the new complex polar difference method (Duncan's test). $\mathrm{R}$ (3.6.0) language (vegan, mvpart, ggplot2 and graphics packages) was used to perform principal coordinate analysis (PCOA) and Pearson and Spearman correlation analyses. Permutational multivariate analysis of variance (PERMANOVA) and variance partitioning analysis (VPA) were based on the Bray-Curtis distance using the adonis and varpart functions within the R package vegan, respectively (Oksanen et al. 2012).

\section{Results}

Effects of pineapple rotation and residue amendment on banana Fusarium wilt disease incidence and relative abundance of Fusarium

The effects of different concentrations of pineapple and banana residues $(0.1 \%, 1.0 \%$ and $10.0 \%)$ on spore germination were evaluated (Fig. 2A). The infusion of all parts of banana had a promoting effect on spore germination of the pathogen, while the infusion of all parts of pineapple had an inhibiting effect on spore germination, with the fruit infusion of pineapple having a highly significant effect on spore

Page 5/18 
germination. The effect of pineapple and banana root exudates on spore germination, compared to banana root exudates, pineapple root exudates were significantly less able to promote spore germination of the pathogen. The fungus significantly increased the number of pathogenic spores compared to the control (Fig. 2B). We observed an overall significantly reduced Fusarium wilt disease incidence in both the pineapple rotation and residue amendment systems (Duncan's $t$-test, $p<0.001)(\operatorname{Pr}$ and $\mathrm{Pp}$ ), which was significantly lower than those in the fallow and monoculture treatments $(p<0.001)$ (Fig. 2C). Moreover, the abundance of rhizosphere Fusarium (rotation treatment) $(p=$ $0.001)$, as indicated by the residue treatment bulk Fusarium $(p=0.118)$, and the relative abundance of rhizosphere Fusarium $(p<0.001)$ were both positively correlated with banana Fusarium wilt DI (Fig. 2D), demonstrating disease suppression ability after rotation and residue addition with pineapple in the banana orchard. In the rhizosphere soil, the relative abundance of Fusarium was significantly lower in the rotation than in the monoculture treatments $(p<0.05$, Fig. $2 \mathrm{C}$ ). The qPCR results showed that significantly fewer Fusarium oxysporum were detected in the rotation rhizosphere (Duncan's t-test, $p<0.05$, Fig. S1).

Effects of pineapple rotation and residue amendment on soil microbial community structure

The PCoA plots (Fig. 3A, B, C and D) showed significant differences in the bacterial and fungal community composition in the rotation and residue amendment systems (PERMANOVA, $p<0.001)$, in the rotation system, there was a significant difference in bacteria $(p$ (bulk) $<0.01$, $p$ (rhizosphere) $<0.01$ ), moreover, the different rhizosphere soil microbial communities changed significantly from the corresponding initial soil microbial communities, and the microbial communities of different plants grown under the same soil type also differed significantly ( $p$ $<0.001$ ) (Fig. S2). The sequencing results were analysed and detailed, and the microbial community richness and diversity sequencing results are shown in the Supplementary Material (Table S3). PERMANOVA and VPA analyses revealed that soil rhizosphere microbial communities were significantly influenced by soil type $(p<0.001)$ and soil $\mathrm{pH}(p<0.001)$. The relative importance of soil type and its soil $\mathrm{pH}$ on soil and rhizosphere microbial communities was greater than that of plant species (Fig. $3 \mathrm{E}, \mathrm{F}, \mathrm{G}$ and H).

Effect of pineapple rotation and residue amendment on taxonomic composition

Volcano plot analysis of the sequence results revealed rotation and residue amendment bacterial and fungal community compositions with specific respective sets of OTUs (Fig. 4A and B). With red indicating bulk soil and black indicating rhizosphere soil, we found both that the pineapple rotation residue amendment treatment had a higher OTU number in the bulk soil, and selecting an OTU with a relative abundance greater than $0.1 \%$ for Venn analysis revealed that rotation and residue treatments had more bacteria, while fungi in the bulk soil had significantly higher OTU numbers than those in the rhizosphere soil (Fig. 4C and D).

At the phylum level, the pineapple rotations and residue amendment, which had the same composition, consisting mainly of the bacterial phyla Proteobacteria, Acidobacteria, Bacteroidetes, Firmicutes, Gemmatimonadetes, Actinobacteria, Verrucomicrobia, Chloroflexi, Planctomycetes, Cyanobacteria/Chloroplast, and Thaumarchaeota and the fungal phyla Ascomycota, and Basidiomycetes, had the most abundant phyla in all samples (Fig. $5 \mathrm{~A}$ and $\mathrm{B}$ ). The pathogens were significantly negatively correlated with the bacterial phyla Thaumarchaeota $\left(-0.482^{\star *}\right)$, Nitrospirae $\left(-0.401^{\star}\right)$, Firmicutes $\left(-0.515^{\star *}\right)$, and Ascomycota $\left(-0.608^{\star \star}\right)$ (Table S5), which were generally consistent with previous findings on disease-suppressing soils (Shen et al. 2018a).

Analysis of the variability of the top 30 genera of bacteria and fungi showed that the variability of genera significantly increased in the soil. In the rotation, we found that the Burkholderia, Bacillus, Rhizobium, Sphingosinicella, Pseudomonas and Talaromyces genera were significantly increased in rhizosphere soils and in bulk soil, along with Gemmatimonas, Gp6, Nitrososphaera, Gp7, Penicillium and Mortierella (Fig. 5C). Among them, in the pineapple rotation, there were significant negative correlations with the number of Fusarium, such as Burkholderia spp. (Pearson: -0.558**, Spearman: -0.443**), Pseudomonas spp. (Pearson: NS, Spearman: -0.363*), and Talaromyces spp. (Pearson: $-0.687 * *$, Spearman: $-0.530 * *$ ) (Tables S6 and S8).

In the residue amendment, we discovered that the Pseudomonas, Sphingobium, Azohydromonas, Bacillus, Georgfuchsia, Rhizobium, Pseudoduganella, Klebsiella, Sphingomonas, Elaphocordyceps and Penicillium genera were significantly increased in rhizosphere soils, in the bulk soil, the Gemmatimonas, Gp6, Nitrososphaera, Opitutus, Gp3, GpXIII, Aspergillus and Chaetomium genera were significantly increased (Fig. 5D). Among them, in the residue treatment, there were significant negative correlations with the number of Fusarium, such as Pseudomonas spp. (Pearson: -0.524**, Spearman: -0.440**), Aspergillus spp. (Pearson: -0.378*, Spearman: $-0.354^{\star}$ ), and Penicillium spp. (Pearson: $-0.453^{\star *}$, Spearman: $-0.540^{\star *}$ ) (Tables S7 and S8).

Bulk and rhizosphere network construction through effects on specific microbial taxa

In this study, we constructed co-occurrence networks using random matrix theory (RMT) to determine the differences in bacterial and fungal assemblages (OTU relative abundance $>0.1 \%$ ) in bulk and rhizosphere soils of the different treatments. All values of the calculated modularity index were larger than 0.4 (Table S9), suggesting typical module structures (Chen et al., 2020). Overall, pineapple rotation and 
residue amendment showed marked effects on the soil microbial network: the average path distance (GD), the average clustering coefficient (avgCC) and the modularity of the empirical networks were higher than those of the corresponding, identically sized random networks (Table S9). Here, we found that residue assemblages (in Fig. $6 \mathrm{C}$ and D) formed more connected and more complex networks with fewer nodes but more connections (edges) between nodes compared with the bulk soil. There were many keystone taxa in the microbial communities whose removal could cause a dramatic shift in microbiome structure and function. Keystone taxa in network analysis can be computationally identified as hubs with a high within-module degree $\mathrm{Zi}(\mathrm{Zi} \geq 0.5$ indicates that the nodes are "well connected" to other nodes in the module). The PBr and PRr treatments had some keystone taxa, such as Burkholderia and Pseudomonas, and no hub was found in the bulk or rhizosphere soil (Cf, Cn, Bm and Bb) (Fig. S3).

Effects of the soil properties, number of F.oxysporum, the bulk and rhizosphere microbial communities and key microorganism on banana Fusarium wilt disease incidence

To investigate the potentially relative important suppression predictors of banana Fusarium wilt disease incidence, we then used Linear models (LM) to identify the potential positive or negative effects of the number of Fusarium (including the number of F.oxysporum and the relative abundance of Fusarium), bacterial and fungal communities (including bulk and rhizosphere communities), and key microorganism Burkholderia, Pseudomonas, Talaromyces and Pseudomonas, Penicillium, Aspergillus (bulk and rhizosphere soil) in the crop rotation and residue amendment system on banana Fusarium wilt disease incidence, respectively (Table 1).

For microbial linear model in the banana-pineapple rotation system, importantly, Fungal-pcoa1 (rhizosphere) $(F=23.41, p=0.001$, Relative Importance $=10.89 \%)$, Fusarium relative abundance (rhizosphere) $(\mathrm{F}=201.74, p<0.001$, Relative Importance $=12.70 \%)$, Burkholderia (rhizosphere) $(F=3.56, p=0.092$, Relative Importance $=13.79 \%)$, Talaromyces (bulk) $(F=64.34, p<0.001$, Relative Importance $=23.61 \%)$ and Talaromyces (rhizosphere) $(F=1.41, p=0.265$, Relative Importance $=19.09 \%)$ constrained disease incidence the most (with a relative importance more than 10\%). Besides, based on linear regression analyses between disease incidence and selected microbial indicators, Fungal-pcoa1 (rhizosphere) $(p=0.001)$, Fusarium relative abundance (bulk) $(p<0.001)$, Fusarium relative abundance (rhizosphere) ( $p<$ $0.001)$ and Talaromyces (bulk) $(p<0.001)$ have significant negative relationship to disease incidence (Table 1$)$.

For microbial linear model in the pineapple residue amendment system, importantly, Fusarium relative abundance (rhizosphere) $(\mathrm{F}=$ 363.96, $p<0.001$, Relative Importance $=25.49 \%$ ) and Aspergillus (rhizosphere) $(F=16.15, p=0.003$, Relative Importance $=40.83 \%)$ constrained disease incidence the most (with a relative importance more than 10\%). Besides, based on linear regression analyses between disease incidence and selected microbial indicators, Penicillium (bulk) $(p=0.051)$ and Aspergillus (rhizosphere) $(p=0.003)$ have significant negative relationship to disease incidence (Table 1).

For physicochemical linear model, the content of soil organic matter $(F=8.94, p=0.011$, Relative Importance $=22.22 \%)$, the available potassium $(F=19.45, p=0.001$, Relative Importance $=36.45 \%)$ and the available phosphorus $(F=89.40, p<0.001$, Relative Importance $=$ $16.37 \%)$, the available potassium $(F=223.59, p<0.001$, Relative Importance $=28.88 \%)$ and the available nitrogen $(F=7.69, p=0.016$, Relative Importance $=45.10 \%$ ) constrained disease incidence the most (with a relative importance more than $10 \%$ ) in the rotation and residue amendment system, respectively (Table S10).

Based on the above results, a conceptual model illustrating potentially path with important suppression predictors in intercropping system was constructed (Fig. 7). The conceptual mode indicated that two ways in banana plantations reduced the relative abundance of Fusarium by the soil characteristics and microbial community structure regulation. Among all the suppression predictors, the key physicochemical factors AP (in rotation system) and OM (in residue system) contents are significantly affected by pineapple rotation and rseidue amendment, respectively. And they were significant leading to changes of fungal community and beneficial microorganism. And the significant increases in bacterial genera (Burkholderia) and fungal genera (Talaromyces and Aspergillus) can directly affect the relative abundance of Fusarium, thereby reduce the incidence of banana (Fig. 7).

\section{Discussion}

Banana with different crop rotations can effectively reduce banana Fusarium wilt (Hong et al. 2020; Fan et al. 2020). In this study, the results of pot experiments revealed that pineapple-banana rotation and residue amendment systems could significantly enhance the suppression of Fusarium wilt disease compared with banana monocropping and residue addition. This pattern is consistent with the results reported in a previous field study (Wang et al. 2015). Notably, through the study of microbial community changes, we found that the reduction in disease incidence in crop rotation and residue amendment treatments could be attributed to a reduction in the number of Fusarium as well as an increase in beneficial genera and changes in soil physicochemistry. We propose two systems in which rotation and residue amendment could inhibit fungal infections. Similar results have been shown for strawberry soil disease (Fang et al. 2012), likely

Page $7 / 18$ 
due to the interruption of the host pathogen cycle in the root. Both high-throughput sequencing and qPCR showed that the Fusarium number was smaller in the pineapple rotation and residue amendment treatments than in the banana monoculture and residue addition and exhibited significant positive correlations with disease incidence in our study (Fig. 2 and Fig. S1). The incorporation of both pineapple residues (P_L, P_R and P_F) into the soil was found to significantly decrease the pathogen density in the soil and the incidence of Fusarium wilt disease. This finding aligns with our previous studies showing that using a pineapple-banana crop rotation system can effectively minimize the incidence of this pathogen (Wang et al. 2015). This study thus provides strong evidence that pineapple-banana rotation and residue amendment are effective approaches for suppressing disease.

In our study, pineapple rotation may have resulted in a significant decline in pathogen number via increased abundance of some beneficial microorganisms and disease suppression by antagonistic and nutritional competition with harmful microorganisms, parasitism, predation, induction of plant resistance, and interference with pathogenic signals, leading to a decrease in nutrient availability to pathogens. In addition, it seems possible that pineapple crops can stimulate beneficial bacterial microbiomes through root exudates to suppress pathogens during the crop rotation season (Hao et al. 2010).

The composition of the rhizosphere fungal community was clearly divided into different groups based on the PCoA results of the crop rotation and residue amendments, the fungal communities were clearly clustered between the pineapple-banana rotation and residue pineapple addition treatments and the banana continuous crop and banana residue addition treatments (Fig. 3). We hypothesize that soil fungi are less redundant than bacteria when exposed to environmental stresses of crop rotation and under the effective nutrients of residue addition. Additionally, VPA analysis showed that the variations in bacterial and fungal communities were best explained by the type of soil, followed by the pattern of cultivation. It has been previously reported that cultivated crops have a greater impact on microbial structure than cultivation patterns. Future research elucidating the mechanisms of plant species-root exudate-soil microbial community interactions may be an effective way to study the suppression of pathogens. Specifically, in our experiment, this suppressive status emerged as a function of changes in the soil fungal communities rather than one that was mediated by changes in soil physicochemical properties. This was also further corroborated by Linear models (LM), which traced the relationships among microbial communities, pathogen density and banana disease incidence (Table S10).

Consistent with previous findings, at the phylum level of bacteria and fungi, the major phyla were Proteobacteria, Acidobacteria, Bacteroidetes, Firmicutes, Gemmatimonadetes, Actinobacteria, Verrucomicrobia, Chloroflexi, Planctomycetes, Cyanobacteria/Chloroplast, and Thaumarchaeota, and the fungal phyla were Ascomycota and Basidiomycetes (Fig. 5A and B). In this study, only the relative abundance of Firmicutes and Ascomycota increased after pineapple rotation and residue addition and showed a strong negative correlation with F. oxysporum abundance (Table S5). This finding suggests that Firmicutes and Ascomycota may be involved in disease suppression through the production of biocontrol agents.

The pineapple-banana rotation significantly stimulated the relative abundance of the Burkholderia, Pseudomonas and Talaromyces genera in the bulk and rhizosphere soils (Fig. 5C and Fig. S2). These microorganisms showed significantly negative correlations with the abundance of F. oxysporum, and there is a large body of work demonstrating the stable suppression of disease by these beneficial microorganisms. For example, Burkholderia spp. has been shown to be abundant in golden pineapple-banana rotations (Wang et al. 2015), and Pseudomonas spp. plays a key role in pathogen antagonism by stimulating the synthesis of a beneficial microbiome common to the native beneficial microorganisms in the soil, after the application of bioorganic fertilizers, to reduce the number of Fusarium in bananas (Hong et al. 2020). Thus, they are widely reported as biological control agents. These microorganisms are capable of producing antifungal metabolites and can colonize the roots of plants, making them targets for biocontrol. Additionally, studies have shown that some fungal microorganisms pre-empt the microecological environment with pathogens, such as the effect of the mass production of Talaromyces spp. on pathogens populations (Bahramian et al. 2016). This result is the same as that reported by Xiong et al. (2017b), who studied two treatments of vanilla wilt, where the crop rotation treatment significantly reduced the number of Fusarium oxysporum in the soil. In addition, both pineapple crop rotation and residue addition significantly reduced the incidence of banana seedling wilt, closely related to the decrease in the number of Fusarium oxysporum in the soil after pineapple cultivation.

According to Wang et al. (2015), golden pineapple rotation can increase the organic matter and available phosphorus content in the soil, with a decrease in the soil $\mathrm{pH}$, the results of this experiment after planting pineapple were consistent with previous studies. PCoA, volcano plot and VPA analyses revealed significant differences in microbial community structure after pineapple rotation, which is consistent with the results of Wang et al. (2015), indicating that crop rotation did change the soil microbial community composition (Zhalnina et al. 2018; Wright et al. 2014; Su et al. 2015).

Plant and soil microflora have important roles in fighting soil-borne diseases (Hong et al. 2020). The species and number of beneficial microflora in soil microorganisms are crucial for suppressing pathogens (Shen et al. 2013; Tian et al. 2020). At the bulk and rhizosphere 
soil bacterial and fungal genus levels, the pineapple rotation treatment significantly increased the numbers of Burkholderia, Pseudomonas, Penicillium, and Talaromyces, in the residue amendment, Pseudomonas, Elaphocordyceps, and Aspergillus significantly reduced the relative abundance of Fusarium oxysporum in the soil. Wang et al. (2015) and Steensels et al. (2019) showed that the numbers of culturable bacteria and Burkholderia increased significantly, and the number of Fusarium oxysporum decreased significantly in pineapple rotation with bioorganic fertilizer. In herb and "maize-potato" rotations, we found that the Pseudomonas genus was abundant and significantly suppressed Fusarium oxysporum populations (Xiong et al. 2017a; Li et al. 2019). Studies have shown that Talaromyces and Aspergillus can have multiple plant protection functions and are corresponding antagonists against plant diseases (Zhai et al. 2015; Naraghi et al. 2010; Moreno et al. 2005). Although Talaromyces and Aspergillus are fungal diseases in some crops, a significantly negative correlation was found between these two genera and Fusarium oxysporum in this experiment, which may be because the fungi Talaromyces and Aspergillus compete with Fusarium oxysporum for nutrients in the soil, resulting in a decrease in the number of Fusarium oxysporum, the exact cause of which needs to be further investigated.

The incidence of banana seedlings replanted after pineapple residue addition was highly significant and positively correlated with Fusarium oxysporum and culturable Fusarium oxysporum, except that it was significantly and negatively correlated with soil pH, Pseudomonas, and Aspergillus and significantly and negatively correlated with culturable bacteria. Penicillium and Burkholderia were abundantly present in the bulk and rhizosphere soils after pineapple residue addition, while Talaromyces and Aspergillus could pass through the pineapple rhizosphere to the soil and then survive in the next banana soil, and Talaromyces could colonize the next banana soil. Therefore, they are also potential key microorganisms (Baileya and Lazarovitsb 2003). In summary, these results provide some directions for our next work and further research on the mechanism of banana-pineapple crop rotation and residue amendment.

\section{Conclusion}

Our rotation pot experiment further demonstrated the effectiveness of banana-pineapple rotation in alleviating banana wilt (Wang et al. 2015). In addition, our study contributes to this body of research by showing that the addition of pineapple plant residues in the soil can trigger soil suppression of a serious soil-borne pathogen (Fusarium spp.). Here, we described that this state of suppression is modulated by changes in the soil bacterial and fungal communities and highlighted one bacterial taxa (Burkholderia spp.) and two fungal taxa (Aspergillus spp. and Talaromyces spp.) that may be directly involved in pathogen suppression. We provided further evidence for their suggested different and complementary modes of action and subsequently validated their suppressive potential in well-controlled indoor experiments (Fig. 2A, B), which offers great promise for the search for beneficial substances in root exudates and residues in the future.

Taken together, our research may provide new avenues for exploring agricultural practices with a focus on beneficial outcomes that directly affect soil health and crop productivity in a viable and sustainable manner.

\section{Declarations}

\section{Conflict of interest}

The authors declare no conflicts of interest.

\section{Acknowledgements}

We are very grateful to Nanjing Personal Biotechnology Co., Ltd for deep 16S rRNA and ITS barcod-ed Illumina sequencing. In addition, we thank all staff members in the Hainan Key Laboratory for Sustainable Utilization of Tropical Bio-resources for their considerable help with banana and pineapple planting and management. This research was financially supported by The National Natural Science Foundation of China (41867006, 42090065 and 31972509), the Hainan Provincial Fundation of China (320RC483) and the National Key Research Development program (2017YFD0202101).

\section{Authors' contributions}

Jinming Yang: Conceptualization, Methodology, Software, Visualization, Writing - review \& editing. Zongzhuan Shen: Resources, Supervision, Funding acquisition. Xiangyu Ren: Resources, Supervision. Wei Gao: Resources, Supervision. Yutong Wang: Resources, Supervision. Manyi Liu: Resources, Supervision. Shan Hong: Resources, Supervision. Mingze Sun: Resources, Supervision. Yan Zhao: Resources, Supervision. Yunze Ruan: Resources, Supervision. Beibei Wang: Investigation, Conceptualization, Methodology, Visualization, Writing - review \& editing, Supervision, Funding acquisition.

\section{References}


1. Afshan S, Ali S, Bharwana SA, Rizwan M, Farid M, Abbas F, Ibrahim M, Mehmood MA, Abbasi GH (2015) Citric acid enhances the phytoextraction of chromium, plant growth, and photosynthesis by alleviating the oxidative damages in Brassica napus L. Environ Sci Pollut R 22:11679-11689

2. Bahramian D, Naraghi L, Heydari A (2016) Effectiveness of the chemical stabilizers of talaromyces flavus in biological control of tomato and greenhouse cucumber vascular wilt disease. J Plant Prot Res 56:0045

3. Baileya KL, Lazarovitsb G (2003) Suppressing soil-borne diseases with residue management and organic amendments. Soil Till Res 72:169-180

4. Bender SF, Wagg C, van der Heijden MGA (2016) An underground revolution: biodiversity and soil ecological engineering for agricultural sustainability. Trends Ecol Evol 31:440-452

5. Bonanomi G, Lorito M, Vinale F, Woo SL (2018) Organic amendments, beneficial microbes, and soil mcrobiota: toward a unified framework for disease suppression. Annu Rev Phytopathol 56:1-20

6. Butler D (2013) Fungus threatens top banana. Nature 504:195-196

7. Caporaso JG, Kuczynski J, Stombaugh J, Bittinger K, Bushman FD, Costello EK, Fierer N, Gonzalez Peña A, Goodrich JK, Gordon JI, Huttley GA, Kelley ST, Knights D, Koenig JE, Ley RE, Lozupone CA, McDonald D, Muegge BD, Pirrung M, Reeder J, Sevinsky JR, Turnbaugh PJ, Walters WA, Widmann J, Yatsunenko T, Zaneveld J, Knight R (2010) QIIME allows analysis of high-throughput community sequencing data. Nat Methods 7:335-336

8. Chen J, Heiling M, Resch C, Mbaye M, Gruber R, Dercon G (2018) Does maize and legume crop residue mulch matter in soil organic carbon sequestration? Agric Ecosyst Environ 265:123-131

9. Chen Y, Bonkowshi M, Shen Y, Griffiths BS, Jiang YJ, Wang XY, Sun B (2020) Root ethylene mediates rhizosphere microbial community reconstruction when chemically detecting cyanide produced by neighbouring plants.Microbiome. 8

10. Christen O, Sieling K (1995) Effect of different preceding crops and crop rotations on yield of Winter Oil-seed rape (Brassica napus L.). J Agron Crop Sci 174:265-271

11. Cunfer BM, Buntin GD, Phillips DV (2006) Effect of crop rotation on take-all of wheat in double-cropping systems. Plant Dis 90:11611166

12. De CU, Patruno L, Avella N, Salimbeni R, Lacolla G, Cucci G, Crecchio C (2020) Soil management under tomato-wheat rotation increases the suppressive response against Fusarium wilt and tomato shoot growth by changing the microbial composition and chemical parameters. Appl Soil Ecol 154:103601

13. Dita C, Waalwijk IW, Buddenhagen MT, Souza JGHJ, Kema A (2010) molecular diagnostic for tropical race 4 of the banana fusarium wilt pathogen. Plant Pathol 59:348-357

14. Edgar RC, Haas BJ, Clemente JC, Quince C, Knight R (2011) UCHIME improves sensitivity and speed of chimera detection. Bioinformatics 27:2194-2200

15. Fan PS, Lai CY, Yang JM, Hong S, Yang Y, Wang Q, Wang BB, Jia ZJ, Zhang RP, Zhao Y, Ruan YZ (2020) Crop rotation suppresses soilborne Fusarium wilt of banana and alters microbial communities.Arch Agron Soil Sci1839058

16. Fang XL, You MP, Barbetti MJ (2012) Reduced severity and impact of Fusarium wilt on strawberry by manipulation of soil pH, soil organic amendments and crop rotation. Eur J Plant Pathol 134:619-629

17. Ge AH, Liang ZH, Xiao JL, Zhang Y, Zeng Q, Xiong C, Han LL, Wang JT, Zhang LM (2021) Microbial assembly and association network in watermelon rhizosphere after soil fumigation for Fusarium wilt control. Agric Ecosyst Environ 312:107336

18. Guo S, Xiong W, Hang XN, Gao ZL, Jiao ZX, Liu HJ, Mo YN, Zhang N, Kowalchuk GA, Li R, Shen QR, Geisen SF (2021) Protists as main indicators and determinants of plant performance. Microbiome 9:64

19. Hao WY, Ren LX, Ran W, Shen QR (2010) Allelopathic effects of root exudates from watermelon and rice plants on Fusarium oxysporum f.sp. niveum. Plant Soil 336:485-497

20. Hong S, Jv HL, Lu M, Wang BB, Zhao Y, Ruan YZ (2020) Significant decline in banana Fusarium wilt disease is associated with soil microbiome reconstruction under chilli pepper-banana rotation. Eur J Soil Biol 97:103154

21. Hu L, Robert CAM, Cadot S, Zhang X, Meng Y, Li B, Daniele M, Noemie C, Van Thomas S dHMGA (2018) Root exudate metabolites drive plant-soil feedbacks on growth and defense by shaping the rhizosphere microbiota. Nature Commun 9:2738

22. Huang YH, Wang RC, Li CH, Zuo CW, Wei YR, Zhang L, Yi GJ (2012) Control of Fusarium wilt in banana with Chinese leek. Eur J Plant Pathol 134:87-95

23. Hwang SC, Ko WH (2004) Cavendish banana cultivars resistant to Fusarium wilt acquired through somaclonal variation in Taiwan. Plant Dis 88:580-588 
24. Kõljalg U, Nilsson RH, Abarenkov K, Tedersoo L, Taylor AFS, Bahram M, Bates ST, Bruns TD, Bengtsson-Palme J, Callaghan TM, Douglas B, Drenkhan T, Eberhardt U, Dueñas M, Grebenc T, Griffith GW, Hartmann M, Kirk PM, Kohout P, Larsson E, Lindahl BD, Lücking R, Martín MP, Matheny PB, Nguyen NH, Niskanen T, Oja J, Peay KG, Peintner U, Peterson M, Põldmaa K, Saag L, Saar I, Schüßler A, Scott JA, Senés C, Smith ME, Suija A, Taylor DL, Telleria MT, Weiss M, Larsson KH (2013) Towards a unified paradigm for sequencebased identification of fungi. Mol Ecol 22:5271-5277

25. Lakshmanan P, Selvaraj P, Mohan S (2008) Efficacy of different methods for the control of Panama disease. Tropical Pest Management 33:373-374

26. Larkin RP (2015) Soil health paradigms and implications for disease management. Annu Rev Phytopathol 53:199-221

27. Larkin RP, Halloran JM (2014) Management effects of disease-suppressive rotation crops on potato yield and soil-borne disease and their economic implications in potato production. Am J Potato Res 91:429-439

28. Li MH, Guo JJ, Ren T, Luo GW, Shen QR, Lu J, Guo W, Ling SW N (2021) Crop rotation history constrains soil biodiversity and multifunctionality relationships. Agric Ecosyst Environ 319:107550

29. Li Y, Guo Q, Wei X, Xue Q, Lai H (2019) Biocontrol effects of Penicillium griseofulvum against monkshood (Aconitum carmichaelii Debx.) root diseases caused by Sclerotium rolfsiii and Fusarium spp. J Appl Microbiol 127:1532-1545

30. Liu LL, Kong JJ, Cui HL, Zhang JB, Wang FH, Cai ZC, Huang XQ (2016) Relationships of decomposability and C/N ratio in different types of organic matter with suppression of Fusarium oxysporum and microbial communities during reductive soil disinfestation. Biol Control 101:103-113

31. Martinez-Feria RA, Castellano MJ, Dietzel RN, Helmers MJ, Liebman M, Huber I, Archontoulis SV (2018) Linking crop- and soil-based approaches to evaluate system nitrogen-use efficiency and tradeoffs. Agric Ecosyst Environ 256:131-143

32. Mawar R, Lodha S (2015) Suppression of soil-borne plant pathogens by cruciferous residues. Organic Amendments and Soil Suppressiveness in Plant Disease Management, In: Meghvansi, M, Varma, A, Eds, Soil Biology: Springer, Cham 46:pp 413-433

33. Mendes LW, Kuramae EE, Navarrete AA, van Veen JA, Tsai SM (2014) Taxonomical and functional microbial community selection in soybean rhizosphere. ISME J 8:1577-1587

34. Mendes R, Garbeva P, Rainmakers JM (2013) The rhizosphere microbiome: significance of plant beneficial, plant pathogenic, and human pathogenic microorganisms. Fems Microbiol Rev 37:634-663

35. Moreno AB, Penas G, Rufat M, Bravo JM, Estopà M, Messeguer J, Segundo BS (2005) Pathogen-induced production of the antifungal AFP protein from Aspergillus giganteus confers resistance to the blast fungus Magnaporthe grisea in transgenic rice. Mol Plant Microbe In 18:951-960

36. Naraghi L, Heydari A, Rezaee S, Razavi M, Khaledi EM (2010) Biological control of tomato verticillium wilt disease by talaromyces flavus. J Plant Prot Res 50:360-365

37. Oksanen J, Blanchet FG, Kindt R, Legendre P, Minchin PR, O'Hara RB, Simpson GL, Solymos P, Stevens MHH, Wagner H (2016) Vegan: Community Ecology Package. R Packageed Version 2.3-3:http://cran.r-project.org/ web/packages/vegan/index.html

38. Ploetz RC (2015) Management of Fusarium wilt of banana: A review with special reference to tropical race 4. Crop Prot 73:7-15

39. Ploetz RC, Churchill ACL (2011) Fusarium wilt: The banana disease that refuses to go away. Acta Hortic 897:519-526

40. Shen ZZ, Penton CR, Lv NN, Xue C, Yuan XF, Ruan YZ, Li R, Shen QR (2018a) Banana Fusarium wilt disease incidence is influenced by shifts of soil microbial communities under different monoculture spans. Microb Ecol 75:739-750

41. Shen ZZ, Ruan YZ, Wang BB, Zhong ST, Su LX, Li R, Shen QR (2015a) Effect of biofertilizer for suppressing Fusarium wilt disease of banana as well as enhancing microbial and chemical properties of soil under greenhouse trial. Appl Soil Ecol 93:111-119

42. Shen ZZ, Ruan YZ, Xue C, Zhong ST, Li R, Shen QR (2015b) Soils naturally suppressive to banana Fusarium wilt disease harbor unique bacterial communities. Plant Soil 393:21-33

43. Shen ZZ, Xue C, Taylor PWJ, Ou YN, Wang BB, Zhao Y, Ruan YZ, Li R, Shen QR (2018b) Soil pre-fumigation could effectively improve the disease suppressiveness of biofertilizer to banana Fusarium wilt disease by reshaping the soil microbiome. Biol Fert Soils 54:793806

44. Shen ZZ, Zhong ST, Wang YG, Wang BB, Mei XL, Li R, Ruan YZ, Shen QR (2013) Induced soil microbial suppression of banana fusarium wilt disease using compost and biofertilizers to improve yield and quality. Eur J Soil Biol 57:1-8

45. Steensels J, Gallone B, Voordeckers K, Verstrepen KJ (2019) Domestication of industrial microbes. Curr Biol 29:R381-R393

46. Su LX, Shen ZZ, Ou YN, Tao CY, Ruan YZ, Li R, Shen QR (2017) Novel soil fumigation strategy suppressed plant-parasitic nematodes associated with soil nematode community alterations in the field. Appl Soil Ecol 121:135-142 
47. Su LX, Ruan YZ, Yang XJ, Wang K, Li R, Shen QR (2015) Suppression on plant-parasitic nematodes using a soil fumigation strategy based on ammonium bicarbonate and its effects on the nematode community. Sci Rep-UK 5:17597

48. Sun JB, Zou LP, Li WB, Yang JH, Wang YJ, Xia QY, Peng M (2018) Rhizosphere soil properties and banana fusarium wilt suppression influenced by combined chemical and organic fertilizations. Agric Ecosyst Environ 254:60-68

49. Tao CY, Li R, Xiong W, Shen ZZ, Liu SS, Wang BB, Ruan YZ, Geisen SF, Shen QR, andKowalchuk GK (2020) Bio-organic fertilizers stimulate indigenous soil Pseudomonas populations to enhance plant disease suppression. Microbiome 8:137

50. Tian BN, Xie JT, Fu YP, Cheng JS, Li B, Chen T, Zhao Y, Gao ZX, Yang PY, Barbetti MJ, Tyler BM, Jiang DH (2020) A cosmopolitan fungal pathogen of dicots adopts an endophytic lifestyle on cereal crops and protects them from major fungal diseases. ISME J 14:31203135

51. Wang BB, Li R, Ruan YZ, Ou YN, Zhao Y, Shen QR (2015) Pineapple-banana rotation reduced the amount of Fusarium oxysporum more than maize-banana rotation mainly through modulating fungal communities. Soil Biol Biochem 86:77-86

52. Wang BB, Shen ZZ, Zhang FG, Raza W, Yuan J, Huang R, Ruan YZ, Li R, Shen QR (2016) Bacillus amyloliquefaciens strain W19 can promote growth and yield and suppress Fusarium wilt in banana under greenhouse and field conditions. Pedosphere 26:733-744

53. Wang BB, Yuan J, Zhang J, Shen ZZ, Zhang MX, Li R, Ruan YZ, Shen QR (2013) Effects of novel bioorganic fertilizer produced by Bacillus amyloliquefaciens W19 on antagonism of Fusarium wilt of banana. Biol Fert Soils 49:435-446

54. Wang M, Pendall E, Fang C, Li B, Nie M (2018) A global perspective on agroecosystem nitrogen cycles after returning crop residue. Agric Ecosyst Environ 266:49-54

55. Wang Q, Garrity GM, Tiedje JM, Cole JR (2007) Naive Bayesian classifier for rapid assignment of rRNA sequences into the new bacterial taxonomy. Appl Environ Microb 73:5261-5267

56. Wang Y, Xu J, Shen J, Luo Y, Scheu S, Ke X (2010) Tillage, residue burning and crop rotation alter soil fungal community and waterstable aggregation in arable fields. Soil Till Res 107:71-79

57. Wei Z, Gu YA, Friman VP, Kowalchuk GA, Jousset A (2019) Initial soil microbiome composition and functioning predetermine future plant health. Sci Adv 5:eaaw0759

58. Wright PJ, Falloon RE, Hedderley D (2014) Different vegetable crop rotations affect soil microbial communities and soil-borne diseases of potato and onion: Literature review and a long-term field evaluation. New Zeal J Crop Hort 43:85-110

59. Xiong W, Guo S, Jousset A, Zhao QY, Wu HS, Li R, Kowalchuk GA, Shen QR (2017a) Bio-fertilizer application induces soil suppressiveness against Fusarium wilt disease by reshaping the soil microbiome. Soil Biol Biochem 114:238-247

60. Xiong W, Li R, Ren Y, Zhao QY, Wu HS, Jousset A, Shen QR (2017b) Distinct roles for soil fungal and bacterial communities associated with the suppression of vanilla Fusarium wilt disease. Soil Biol Biochem 107:198-207

61. Xue C, Shen ZZ, Hao YW, Yu ST, Li YC, Huang WJ, Chong Y, Ran W, Li R, Shen QR (2019) Fumigation coupled with bio-organic fertilizer for the suppression of watermelon Fusarium wilt disease re-shapes the soil microbiome. Appl Soil Ecol 140:49-56

62. Yuan J, Zhao J, Wen T, Zhao M, Li R, Goossens P, Huang Q, Bai Y, Vivanco JM, Kowalchuk GA, Berendsen RL, Shen QR (2018) Root exudates drive the soil-borne legacy of aboveground pathogen infection. Microbiome 6:156

63. Zhai MM, Niu HT, Li N, Xiao H, Shi YP, Di DL, Crews P, Wu QX (2015) Talaromycolides A-C, Novel Phenyl-Substituted Phthalides Isolated from the Green Chinese Onion-Derived Fungus Talaromyces pinophilus AF-02. J Agr Food Chem 63:9558-9564

64. Zhalnina K, Louie KB, Hao Z, Mansoori N, da Rocha UN, Shi SJ, Cho HJ, Karaoz U, Loque D, Bowen BP (2018) Dynamic root exudate chemistry and microbial substrate preferences drive patterns in rhizosphere microbial community assembly. Nat Microbiol 3:470-480

65. Zhang N, He X, Zhang J, Raza W, Yang XM, Ruan YZ, Shen QR, Huang QW (2014) Suppression of Fusarium wilt of banana with application of bio-organic fertilizers. Pedosphere 24:613-624

66. Zhou G, Gao S, Lu Y, Liao Y, Nie J, Cao W (2020) Co-incorporation of green manure and rice straw improves rice production, soil chemical, biochemical and microbiological properties in a typical paddy field in southern China. Soil Till Res 197:104499

\section{Tables}

Table 1 Linear models (LM) for the relationships of microbial indicators with disease incidence and the relative importance of each indicators in the crop rotation and residue amendment system. $P$ was results of ANOVAs. 


\begin{tabular}{|c|c|c|c|c|c|c|c|c|c|c|c|}
\hline Crop rotation & df & $\mathrm{F}$ & $P$ & $r$ & $\begin{array}{l}\text { Relative } \\
\text { importance }\end{array}$ & $\begin{array}{l}\text { Residue } \\
\text { amendment }\end{array}$ & df & $\mathrm{F}$ & $P$ & r & $\begin{array}{l}\text { Relative } \\
\text { importance }\end{array}$ \\
\hline $\begin{array}{l}\text { Bacterial- } \\
\text { pcoa1 (bulk) }\end{array}$ & 1 & 2.35 & 0.159 & 2.06 & $4.19 \%$ & F.oxysporum (bulk) & 1 & 154.60 & 0.000 & 2.33 & $6.44 \%$ \\
\hline $\begin{array}{l}\text { Fungal- } \\
\text { pcoa1 } \\
\text { (rhizosphere) }\end{array}$ & 1 & 23.41 & 0.001 & -2.47 & $10.89 \%$ & $\begin{array}{l}\text { F.oxysporum } \\
\text { (rhizosphere) }\end{array}$ & 1 & 91.47 & 0.000 & 2.27 & $7.95 \%$ \\
\hline $\begin{array}{l}\text { F.oxysporum } \\
\text { (rhizosphere) }\end{array}$ & 1 & 278.24 & 0.000 & 2.05 & $7.73 \%$ & $\begin{array}{l}\text { Fusarium relative } \\
\text { abundance } \\
\text { (rhizosphere) }\end{array}$ & 1 & 363.96 & 0.000 & 2.55 & $25.49 \%$ \\
\hline $\begin{array}{l}\text { Fusarium } \\
\text { relative } \\
\text { abundance } \\
\text { (bulk) }\end{array}$ & 1 & 68.97 & 0.000 & -1.80 & $6.62 \%$ & $\begin{array}{l}\text { Fungal-pcoa1 } \\
\text { (bulk) }\end{array}$ & 1 & 1.89 & 0.203 & -1.50 & $6.78 \%$ \\
\hline $\begin{array}{l}\text { Fusarium } \\
\text { relative } \\
\text { abundance } \\
\text { (rhizosphere) }\end{array}$ & 1 & 201.74 & 0.000 & -3.36 & $12.70 \%$ & $\begin{array}{l}\text { Pseudomonas } \\
\text { (bulk) }\end{array}$ & 1 & 98.76 & 0.000 & 2.70 & $4.85 \%$ \\
\hline $\begin{array}{l}\text { Burkholderia } \\
\text { (rhizosphere) }\end{array}$ & 1 & 3.56 & 0.029 & -2.22 & $13.79 \%$ & Penicillium (bulk) & 1 & 5.06 & 0.051 & -1.48 & $3.48 \%$ \\
\hline $\begin{array}{l}\text { Talaromyces } \\
\text { (bulk) }\end{array}$ & 1 & 64.32 & 0.000 & -3.52 & $23.61 \%$ & Aspergillus (bulk) & 1 & 28.96 & 0.000 & 1.64 & $3.01 \%$ \\
\hline $\begin{array}{l}\text { Talaromyces } \\
\text { (rhizosphere) }\end{array}$ & 1 & 1.41 & 0.265 & 1.19 & $19.09 \%$ & $\begin{array}{l}\text { Aspergillus } \\
\text { (rhizosphere) }\end{array}$ & 1 & 16.15 & 0.003 & -4.02 & $40.83 \%$ \\
\hline Residuals & 9 & & & & & Residuals & 9 & & & & \\
\hline \multicolumn{6}{|c|}{$\begin{array}{l}\text { Model summary: } R^{2}=0.974, A I C=66.00, p< \\
0.001\end{array}$} & \multicolumn{6}{|c|}{ Model summary: $\mathrm{R} 2=0.978, \mathrm{AlC}=53.43, \mathrm{p}<0.001$} \\
\hline
\end{tabular}

Proportion of variance explained by model: $98.62 \%$

Proportion of variance explained by model: $98.83 \%$

\section{Figures}

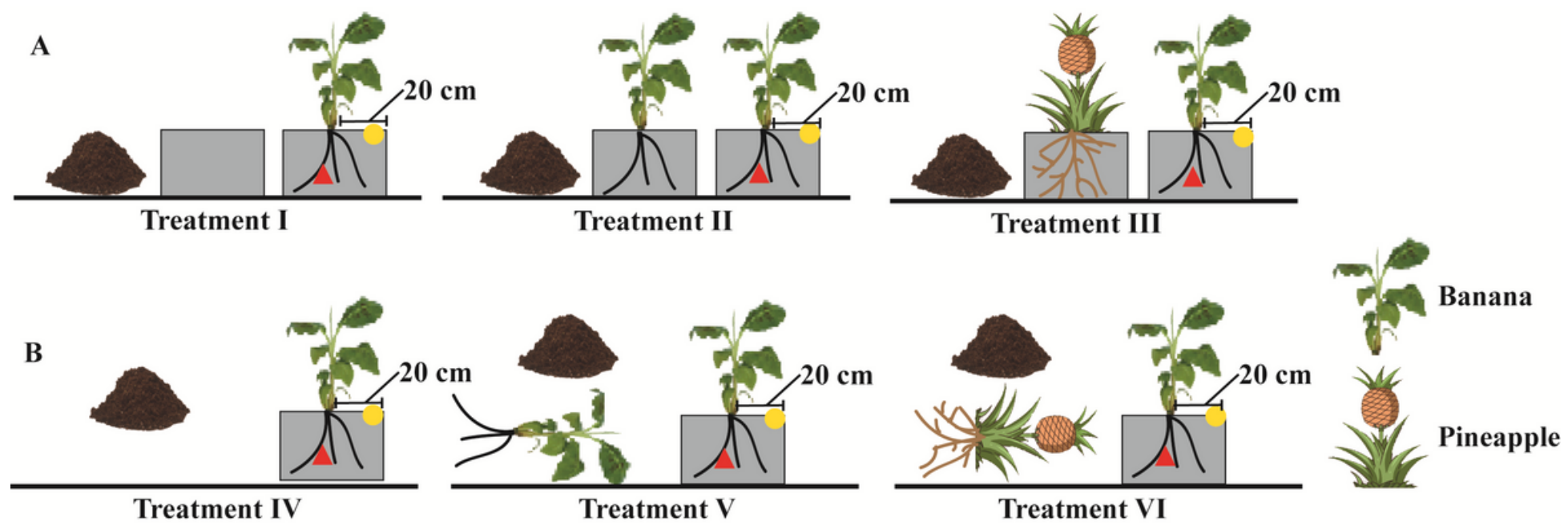

\begin{tabular}{|c|c|c|c|c|c|c|}
\hline Treatment & I & II & III & VI & V & IV \\
\hline \multirow{2}{*}{ Sampling site } & Bulk & Bulk & Bulk & Bulk & Bulk & Bulk \\
& $\Delta$ Rhizosphere & $\Delta$ Rhizosphere & $\Delta$ Rhizosphere & $\Delta$ Rhizosphere & $\Delta$ Rhizosphere & $\Delta$ Rhizosphere \\
\hline \multirow{2}{*}{ Soil sampling } & CBf & BBm & PBr & CBn & BBb & PBp \\
& CRf & BRm & PRr & CRn & BRb & PBp \\
\hline
\end{tabular}




\section{Figure 1}

Diagram of crop rotation, monocropping and residue addition sampling sites in the pot experiments. CBf: fallow in the bulk soil, CRf: fallow in the rhizosphere soil, BBm: banana monoculture in the bulk soil, BRm: banana monoculture in the rhizosphere soil, PBr: pineapple-banana rotation in the bulk soil, PRr: pineapple-banana rotation in the rhizosphere soil, CBn: fallow in the bulk soil, CRn: fallow in the rhizosphere soil, BBb: adding banana residue in the bulk soil, BRb: adding banana in the rhizosphere soil, PBp: adding pineapple in the bulk soil, PBp: adding pineapple in the rhizosphere soil.
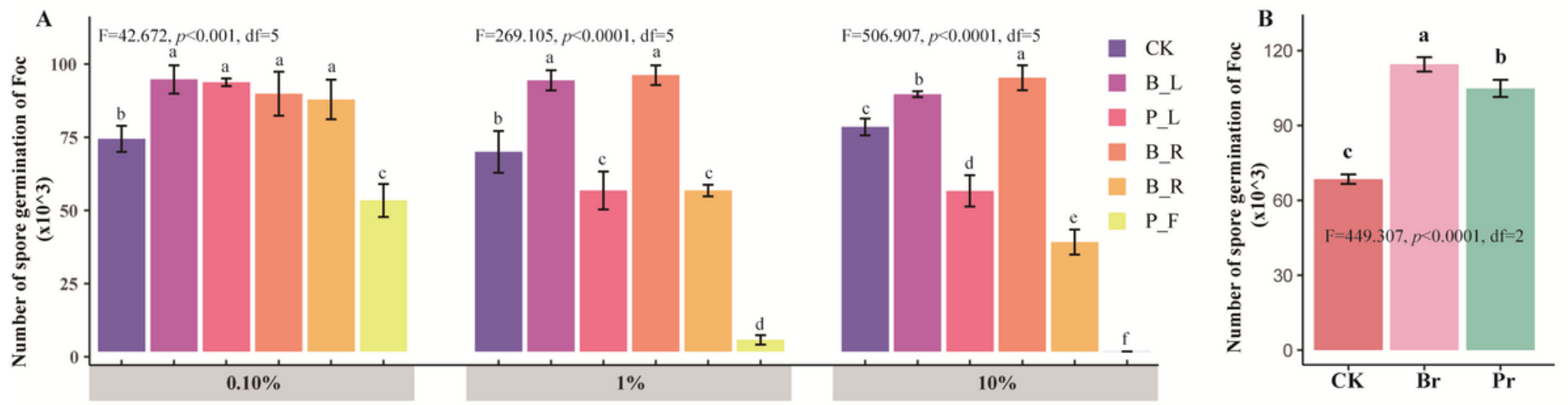

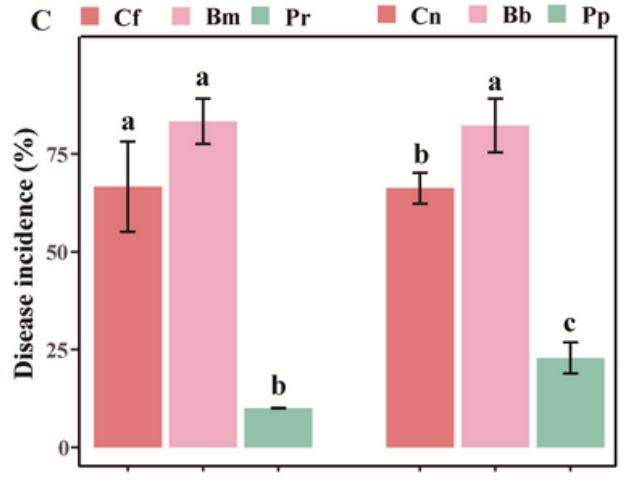

Rotation

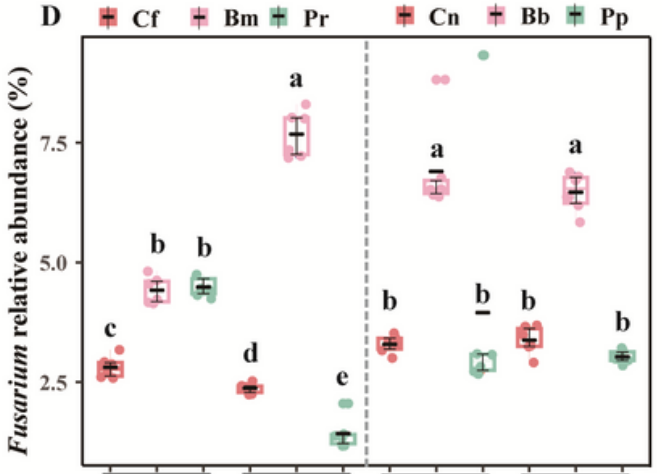

Bulk soil Rhizosphere soil Bulk soil Rhizosphere soil Rotation
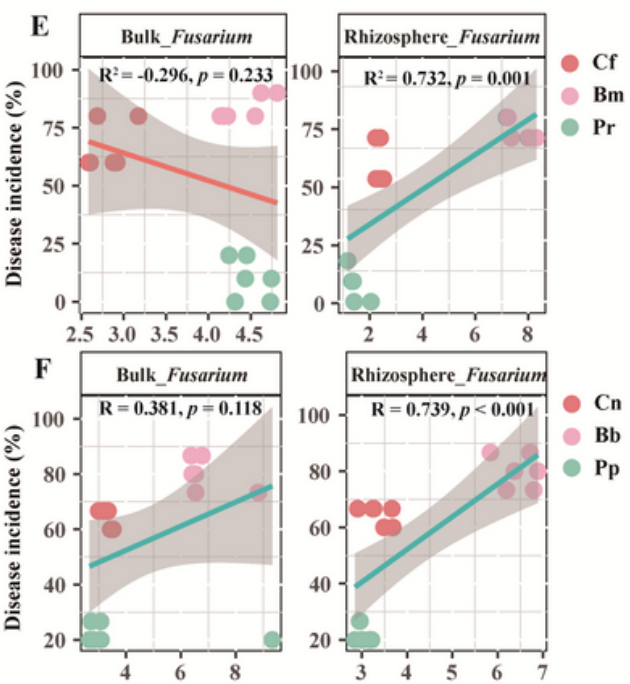

Figure 2

Effects of exudates from pineapple and banana on the spore germination of Foc (A). Effects of root exudates from pineapple and banana on the spore germination of Foc (B). Disease incidence of banana (\%) and the relative abundance of Fusarium (C), and linear regression of DI and pathogen abundance (D) across all samples from six replicates. An asterisk indicates a statistically significant difference $(p<0.05$, $p<0.01, p<0.001)$ based on Duncan's t-test. The treatment abbreviations are defined in Fig. 1. 


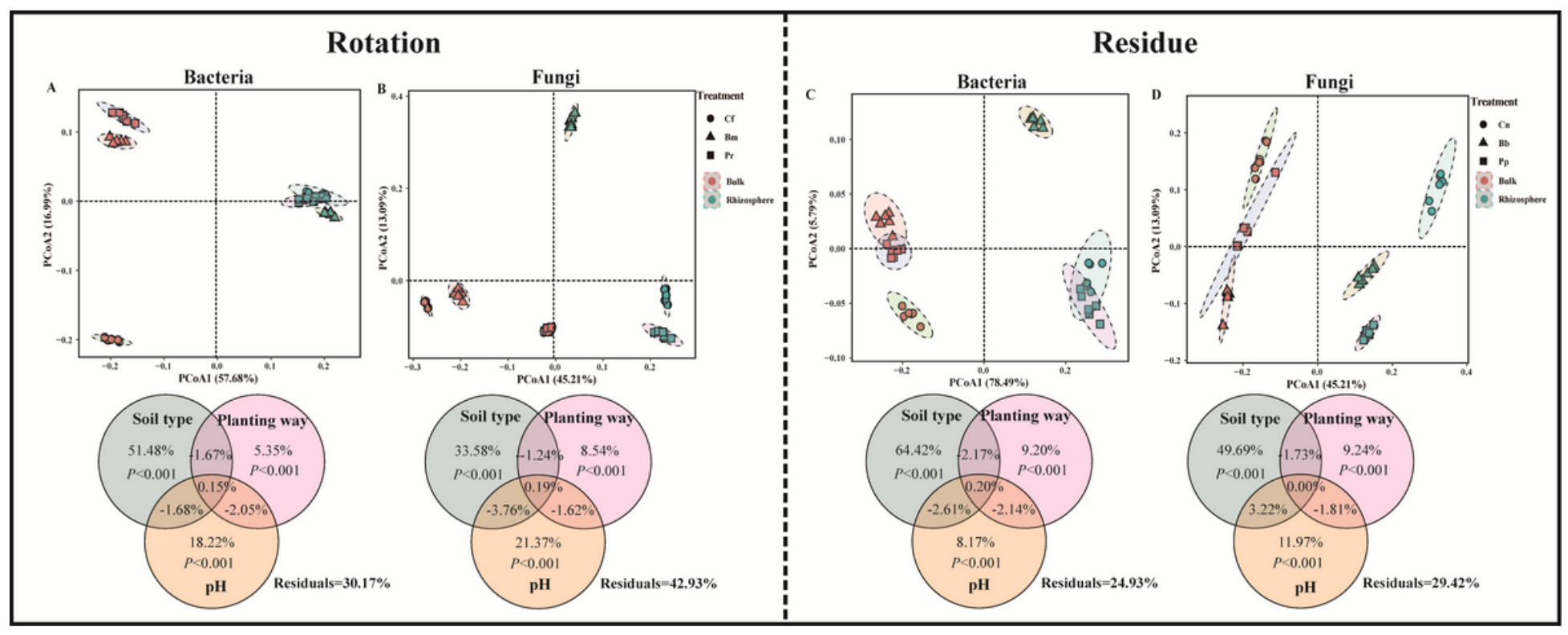

Figure 3

PCoA based on Bray-Curtis distance of rotation (bacteria (A), fungi (B)) and residue (bacteria (C), fungi (D)) of soil community structure. Contributions of soil type, planting method, and soil chemicals $(\mathrm{pH})$ to the assembly of soil bacterial $(\mathrm{E}, \mathrm{G})$ and fungal $(\mathrm{F}, \mathrm{H})$ communities were calculated based on variance partitioning analyses (VPAss) in rotation and residue, respectively, and the p value was determined by PERMANOVA. The treatmentabbreviations are defined in Fig. 1.
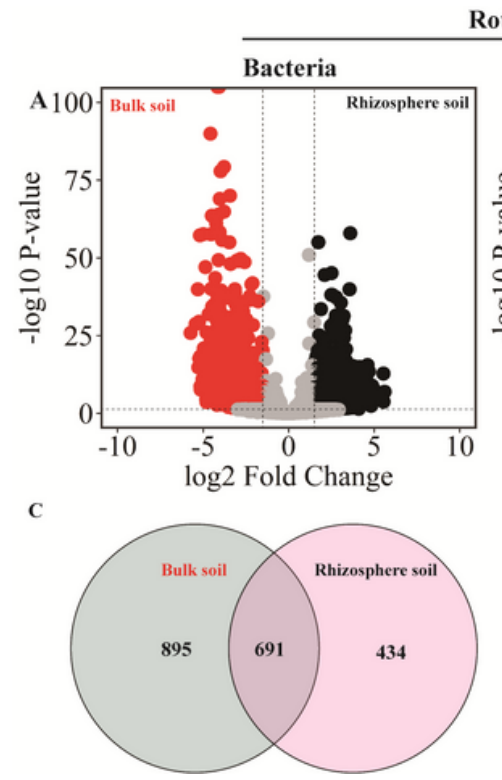

Rotation
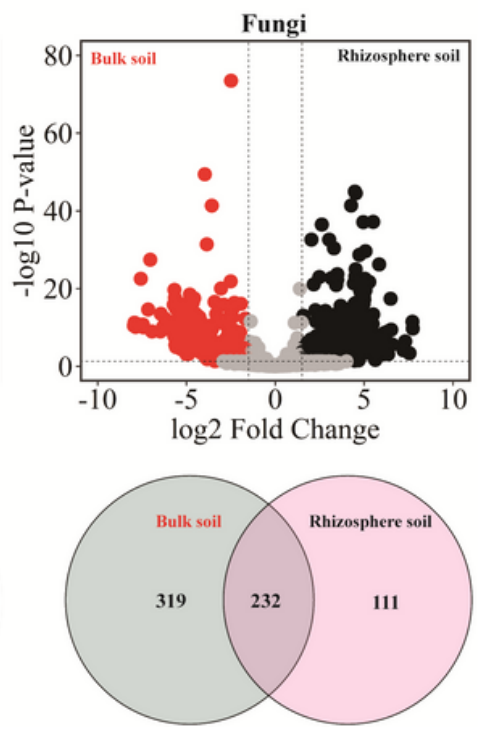

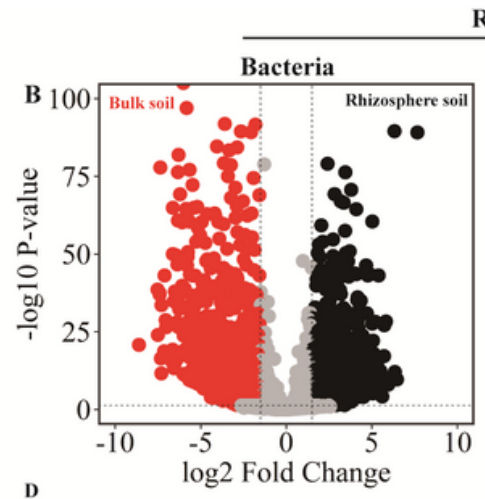

Residuce

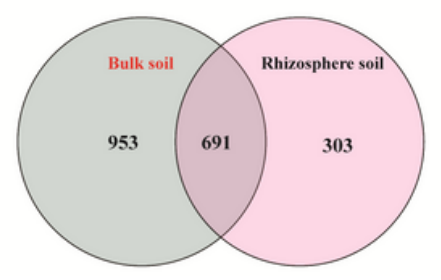

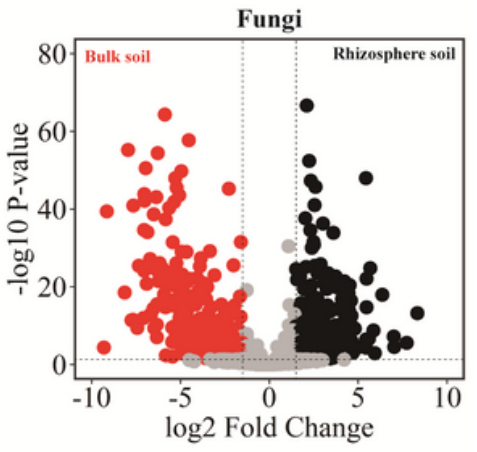

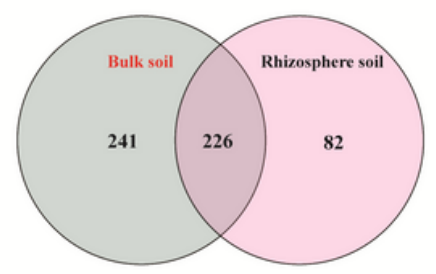

Figure 4

The effects of soil type (bulk and rhizosphere soils) in the pineapple rotation and residue identity (following banana and pineapple cultivation) on microbial compositions. The rotation bacterial (A) and fungal OTUs with relative abundances that were significantly (log2fold change $>|1.5|$ and FDR adjusted $p$ value $<0.05$ ) different between the bulk (red) and rhizosphere (black) soils are coloured in the volcano plot. Venn diagrams $C$ and $D$ represent the numbers of bacterial and fungal OTUs in the bulk and rhizosphere soils originating from the rice soil, respectively. Venn diagrams e and $\mathrm{f}$ represent the numbers of bacterial and fungal OTUs in rhizosphere soils originating from the forest soil, respectively. The treatment abbreviations are defined in Fig. 1. 


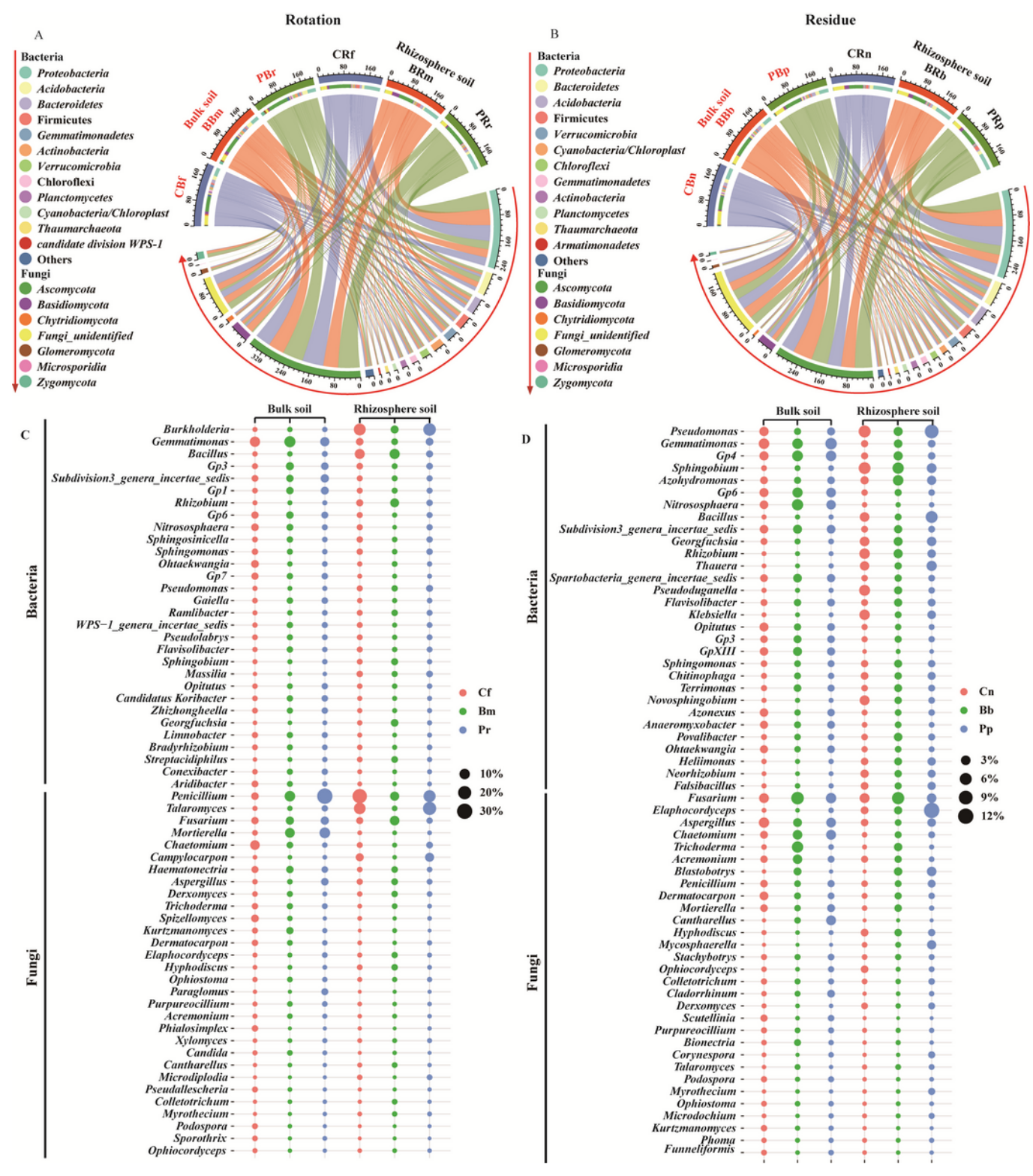

Figure 5

Relative abundances (\%) of the phyla and top 30 genera containing the rotation $(a, c)$ and residue (b, d). Circle sizes in c and d represent the relative abundances of the genera. The treatment abbreviations are defined in Fig. 1. 


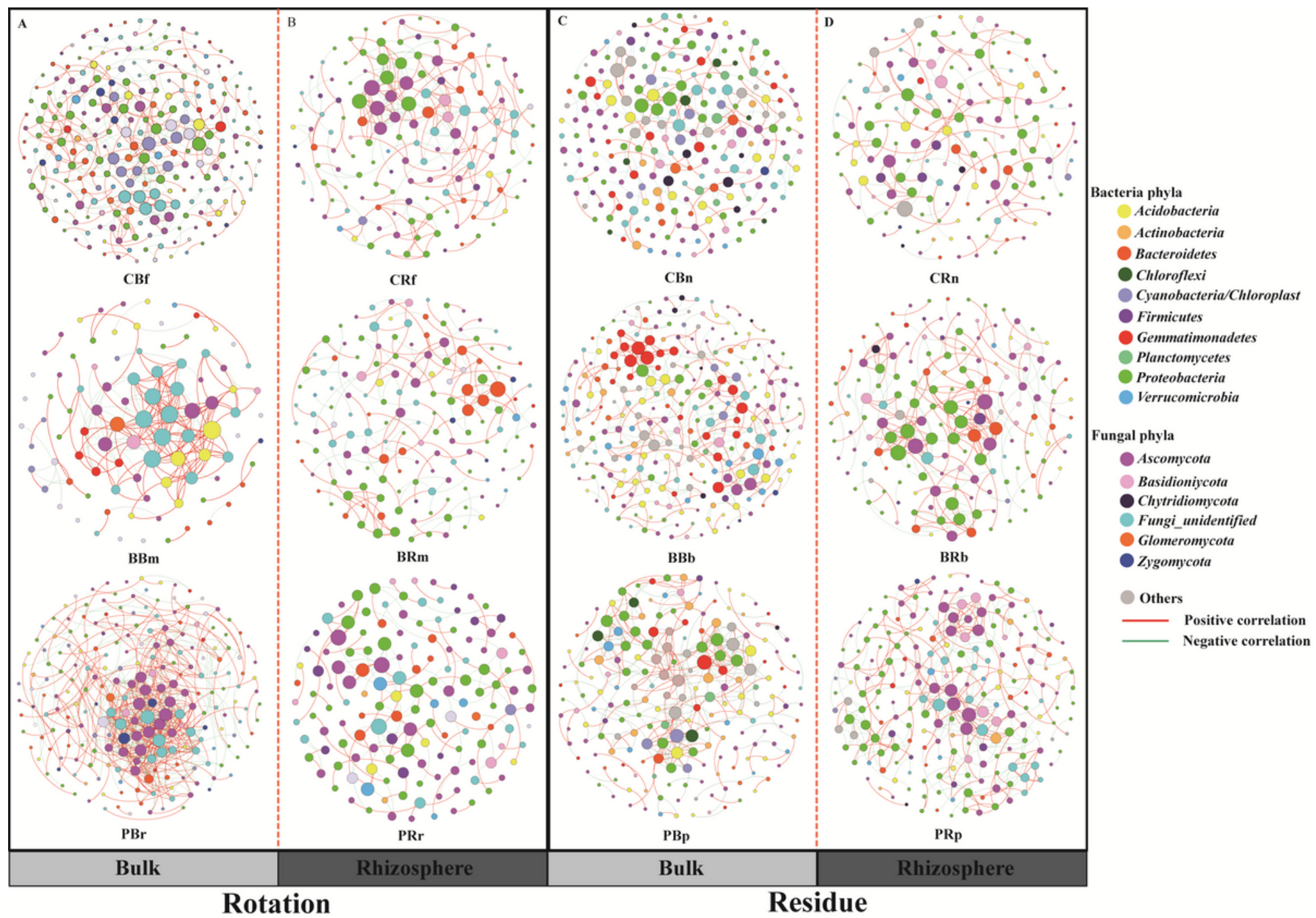

Figure 6

Plant rhizosphere and the corresponding bulk soil networks in the rotation and residue addition systems. Networks represent random matrix theory co-occurrence models derived from 6 biological replicates at each site, where nodes represent OTUs, and the edges between the nodes indicate significant correlations. A green edge indicates a negative covariation between two individual nodes, while a red edge indicates a positive covariation. The treatment abbreviations are defined in Fig. 1. 


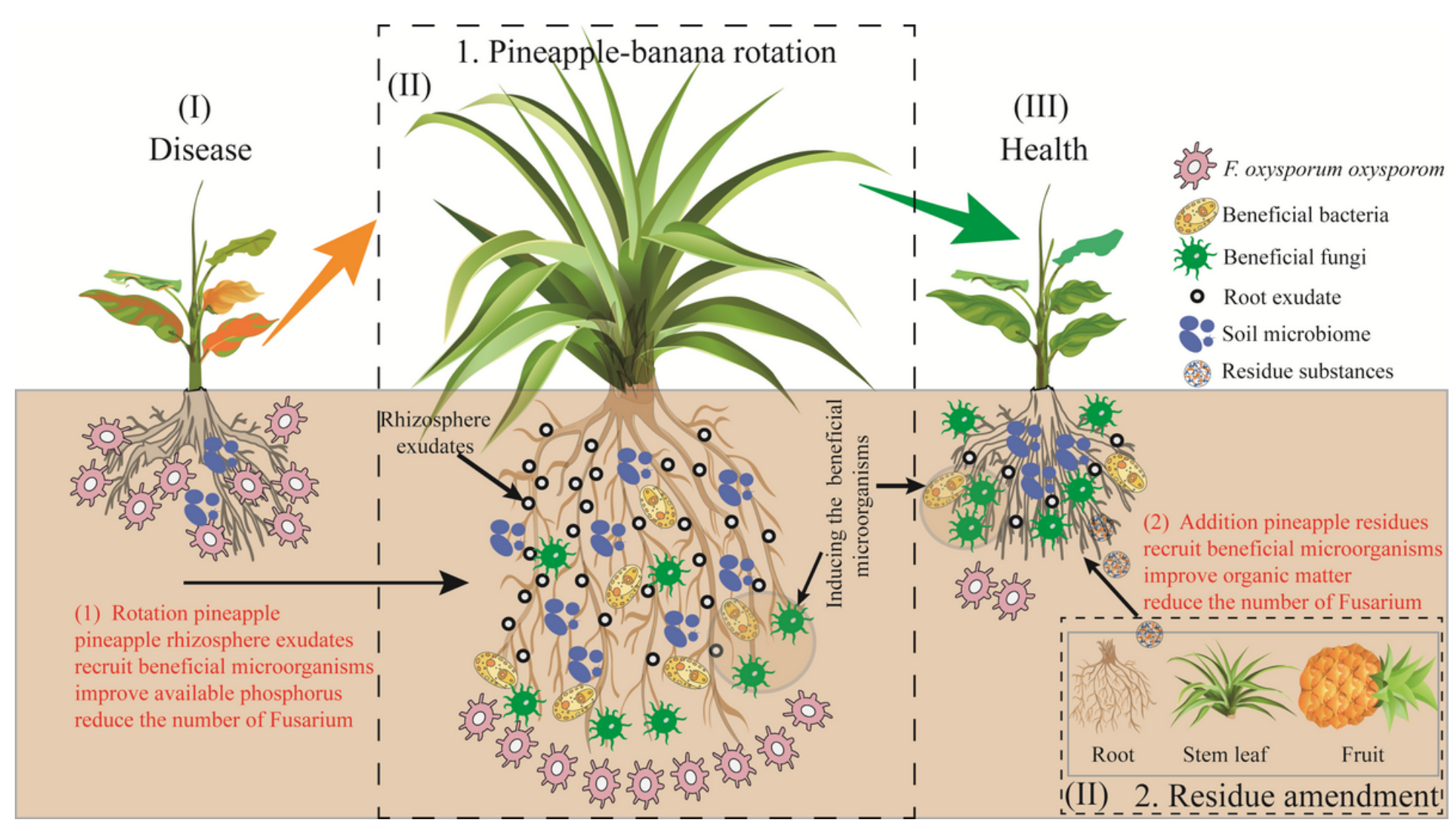

Figure 7

The overview of the mechanism by which pineapple mediates microbiota to increase available nutrients in the banana-pineapple crop rotation and residue amendment system, and reduce the incidence of banana.

\section{Supplementary Files}

This is a list of supplementary files associated with this preprint. Click to download.

- Graphicformanuscript.docx

- SupplementaryMaterials.docx 